\title{
COVID-19-Related Anxiety and the Coping Strategies in the Southeast Ethiopia
}

\author{
Zinash Teferu Engida' \\ Damtew Solomon Shiferaw $\mathbb{D D}^{2}$ \\ Musa Kumbi Ketaro' \\ Ayele Mamo (iD ${ }^{3}$ \\ Ahmednur Adem Aliyi' \\ Abduljewad \\ Hussein Mohamed (iD) ' \\ Mesud Mohammed Hassen ${ }^{3}$ \\ Abdulshakur \\ Mohammed Abduletif ${ }^{4}$ \\ Abate Lette Wodera' \\ Sintayehu Hailu Ayene' \\ Jeylan Kasim Esamael (D) ${ }^{1}$ \\ Habtamu Gezahegn (1D ${ }^{2}$ \\ Adem Esmael (iD) 4 \\ 'Public Health Department, Madda Walabu \\ University Goba Referral Hospital, Bale- \\ Goba, Ethiopia; ${ }^{2}$ Biomedical Department, \\ Madda Walabu University Goba Referral \\ Hospital, Bale-Goba, Ethiopia; ${ }^{3}$ Pharmacy \\ Department, Madda Walabu University \\ Goba Referral Hospital, Bale-Goba, \\ Ethiopia; ${ }^{4}$ Nursing Department, Madda \\ Walabu University Goba Referral Hospital, \\ Bale-Goba, Ethiopia
}

Correspondence: Zinash Teferu Engida Email zinut2016@gmail.com
Background: The pandemic of coronavirus disease spreading is impacting mental health globally. Even though the pandemic is challenging for patients, the community, policymakers, as well as health organizations, and teams, the data on COVID-19 and its association with anxiety and coping mechanisms towards infection among community members are currently limited. Thus, the study is intended to assess COVID-19-related levels of anxiety and coping strategies among community members of Bale and East Bale Zones, Southeast Ethiopia.

Methods: A community-based survey was carried out among 634 study participants of Bale and East Bale Zones from June 1 to 20, 2020. The level of anxiety was determined by using the 5-item Coronavirus Scale and the coping strategies were determined by using the 15-item Coping and Adaptation Processing Scale. Interviewer-administered questionnaires were used to collect the data. Bi-variable analysis and multiple logistic regression analysis were used to estimate the relationship among the variables.

Results: COVID-19-related dysfunctional level of anxiety was found 95 (16.58\%). About 290 (50.6\%) respondents were copied from anxiety that occurred as a result of COVID-19. Factors significantly associated with the dysfunctional level of anxiety related to COVID-19 were being an urban resident (AOR $=0.44,95 \% \mathrm{CI}$ : 0.23 , 0.86), those who had no information from TV/radio ( $\mathrm{AOR}=1.76,95 \% \mathrm{CI}: 1.09,2.84$ ), and walking a long distance more than 1 hour from the health institution $(\mathrm{AOR}=0.58$, 95\% CI: 0.34, 0.97).

Conclusion: COVID-19-related dysfunctional levels of anxiety were $16.58 \%$ in the study community. Half of the community was coped with COVID-19-related anxiety. Being an urban resident and walking along distances more than 1 hour from the health facility were the factors that decreased the odds of having a dysfunctional anxiety, whereas respondents who had no information from TV/radio increased the odds of having a dysfunctional anxiety. Accordingly, focusing on these identified factors could improve a dysfunctional level of anxiety in the study community.

Keywords: level of anxiety, coping strategies, COVID-19, Bale Zone, East Bale Zone Ethiopia

\section{Background}

A novel Coronavirus disease (COVID-19) outbreak caused by 2019-nCoV started in China ${ }^{1,2}$ and it has been pandemic globally. ${ }^{3}$

The pandemic of the COVID-19 spreading is impacting mental health globally. People affected by the disease and their close contact with a sudden outbreak of the disease always pose a threat to mental health. Anxiety, depression, anger, and other 
psychological problems are higher among confirmed patients, suspected patients, medical, and related personnel, as well as close contacts with patients.

The absence of face-to-face communication and other regular social interventions during the epidemic outbreak results in stressful conditions. ${ }^{4,5}$ Being alone also results in the feeling of loneliness and anger. ${ }^{6}$ Adjustment disorder and post-traumatic stress disorder can be developed due to these short-term effects. ${ }^{7}$

Globally, many preventive measures have been taken. These include restriction of movement, stay at home, and closure of the school, and other social services that lead to increased anxiety among the society. ${ }^{8,9}$ It has been indicated that the increasing number of patients and suspected cases, as well as the increasing number of provinces and countries affected by the outbreak, have elicited public worry about being infected in this outbreak, which has increased anxiety. ${ }^{10}$

However, nobody is sure when the disease will be under control. The unpredictability of the current crisis and being alone for indefinite periods results in a stressful situation for Ethiopian people. Common mental health problems like anxiety can be increased in stressful situations. ${ }^{11}$

Inappropriate information regarding the COVID-19 epidemic on social media may also lead to a suicide attempt. ${ }^{12}$ A psychiatric intervention follow-up was delivered by the mental health team coping with the outbreak, as suggested by the occurrence of high mortality infectious disease outbreaks. ${ }^{13}$

Apart from the primary source of anxiety that is COVID-19, there may be secondary sources like fear of the scarcity of resources, fear of losing a beloved person, fear of lack of social support, and others. ${ }^{14}$ These psychological difficulties to cope with the current situation are aggravated with the extreme measures taken by the Governments of different countries to decrease the virus spread, especially by keeping people in quarantine.

To the best of our knowledge, the mental health of the general population living in Ethiopia during the COVID19 pandemic is unknown. Accordingly, it is critical that public health decision-makers, health authorities, and health care providers across disciplines understand how health anxiety will influence responses to viral outbreaks, including current responses to COVID-19.

Research examining COVID-19-related level of anxiety and coping strategies due to the epidemic disease is limited, hence, knowing these processes may inform the treatment and prevention of anxiety, ${ }^{15}$ which is associated with increased costs for health and results in reducing the quality of life. $^{16}$

It is also necessary that the detailed mental health status of the community during the epidemic should be collected for the following purposes. To evaluate the mental situation of the community during the epidemic: to provide a theoretical basis for psychological interventions with the community, and to provide a basis for the promulgation of national and governmental policies. There is a paucity of data on COVID-19-related levels of anxiety and coping strategies in the community. Thus, this study is aimed to assess COVID-19-related levels of anxiety and coping strategies in the communities of Bale and East Bale Zone.

\section{Methods}

\section{Study Area and Participants}

The community-based cross-sectional study involving 634 participants was done in the community of the Bale and East Bale Zones, during June 2020. The Bale Zones are found in Oromia Regional State and are located at about $430 \mathrm{~km}$ and $570 \mathrm{~km}$ in the Southeast of the capital city, Addis Ababa, respectively. The Bale Zone has 12 woredas and 2 administrative towns. East Bale Zone has 10 woredas and 1 administrative town. The study was conducted in Bale and East-Bale zones because climatic conditions of Bale and East-Bale zones include Dega (high land and cold), Woinadega (midland and temperate), and Kola (low land and hot) woredas, which is also a university research attachment area.

\section{Population and Eligibility Criteria}

The source population consisted of all residents of the Bale and East Bale Zones. The study population was drawn from the entire population of 22 kebeles by multistage random sampling. All people over the age of 18 were included in the study, except for those who were critically ill, unable to communicate, or had changes in consciousness level or mental problems.

\section{Sample Size Determination}

Because there is a paucity of research on the subject, the sample size was determined using a single population proportion formula with the assumptions of a $95 \%$ level of confidence in the study, a 5\% margin of error, and a proportion $(p)=50 \%$. A design effect of 1.5 and a non- 
response rate of $10 \%$ were also taken into account. We used design effect 1.5 since we assumed the community was homogeneous. ${ }^{17,18}$

\section{Sampling Procedures}

Five woredas and one administrative town were selected randomly from 22 woredas and 3 administrative towns. Then, 22 Kebeles were randomly selected from selected administrative towns and woredas. For each selected kebeles (small administrative unit), households were identified through census and the sampling frame was developed. Finally, the study participants were addressed through simple random sampling by using a sampling frame developed. One participant from each selected household was selected randomly (if there are two or more).

\section{Operational Definition}

Dysfunctional level of anxiety: According to the corona anxiety scale (CAS), if respondents scored 9 and above. ${ }^{19}$

Coped-According to the coping and adaptation process scale (CAPS), if respondents scored 38 and above

\section{Instruments and Data Collection Methods}

Data were collected by interviewing participants using structured interviewer-administered questionnaires. The questionnaire includes tools used to assess socio-demographic characteristics and evaluate the level of COVID19-related anxiety in the preceding two weeks, which were adopted from the Coronavirus Anxiety Scale and coping strategies measured using the Coping and Adaptation Processing Scale. Demographic variables included were age, gender, marital status, role in family, educational level, occupation, average monthly income, house ownership, chronic illnesses, distance from the health facility, current place of residency, and source of information regarding COVID-19. The questionnaires were developed in English and translated into the local language for appropriateness and easiness in approaching the study subjects and back-translated to English by a language expert to check its consistency. The questionnaires were pretested on $5 \%$ of the sample size in kebeles different from those selected sub-kebeles for the study before actual data collection. Based on the findings of the pretest, valuable amendments were done. Using corrected questionnaires, house-to-house data collection was done. The data were collected by six BSc health science graduates and three masters of public health (MPH) professionals who supervised the data collection process. The training was given to the assigned data collectors and supervisors about the assessment tools to maintain data quality.

Coronavirus Anxiety scale is a collection of 20 candidate items that were developed based on the psychology of fear and anxiety literature. ${ }^{20}$ Each item was written to capture a distinct manifestation of this type of anxiety. Each item was scored on a 5-point scale to represent the frequency of the symptoms over the previous two weeks, ranging from 0 (never) to 4 (nearly every day), and the total score was calculated by adding the scores for each of the responses. ${ }^{19}$

In the current study, the CAS has good internal consistency reliability (Cronbach's alpha $=0.696$ )

The Coping and Adaptation Processing Scale: Short Form is a 15-item instrument that encapsulates the CAPS long form's original concepts (47 items). The CAPS Short Form employs a Likert scale with response options ranging from 4 (always) to 1 (never) (never). Each CAPS item is a brief statement about how a person reacts to a crisis or a particularly traumatic event. Total scores are obtained by adding the numeric responses on each item, with a range of 60 to 15 , with a high score suggesting more consistent use of the defined coping strategies (coped). ${ }^{21}$

In the current study, the CAPS has strong internal consistency reliability (Cronbach's alpha=0.799)

\section{Data Management and Analysis}

At each stage of data management, the collected questionnaires were reviewed for completeness and accuracy. Epidata version 3.1 was used to enter data, which was then exported to Stata version 14.1 for analysis. Data cleaning was carried out to ensure precision, consistency, and the absence of missing values and variables. The proportion of COVID-19-related anxiety and coping strategy was calculated using descriptive analysis. Frequency tables and percentages were used as descriptive statistics. Bivariate analysis was used to see which variables have an individual relationship with the dependent variable. In the multiple logistic regression analysis, variables with a p-value of less than 0.25 in binary logistic regression were included.

The technique was ENTER method. To identify statistically significant variables, a 0.05 p-value was used as a cut-off point. The model's goodness was calculated by 
Table I Showing Socio-Demographic Characteristics of the Study Participants in the Communities of Bale and East Bale Zone, Southeast Ethiopia, $2020(n=573)$

\begin{tabular}{|c|c|c|c|}
\hline Variables & Category & Frequency (n) & Percent (\%) \\
\hline \multirow[t]{4}{*}{ Age of respondents in years } & $<25$ years & 129 & 22.5 \\
\hline & $25-34$ years & 213 & 37.2 \\
\hline & $35-44$ years & 105 & 18.3 \\
\hline & $>44$ years & 126 & 22.0 \\
\hline \multirow[t]{2}{*}{ Gender of respondents } & Male & 383 & 66.8 \\
\hline & Female & 190 & 33.2 \\
\hline \multirow[t]{2}{*}{ Residence of respondents } & Rural & 453 & 79.1 \\
\hline & Urban & 120 & 20.9 \\
\hline \multirow[t]{4}{*}{ Level of education of respondents } & No formal education & 145 & 25.3 \\
\hline & Primary education(grade I-8) & 227 & 39.6 \\
\hline & Secondary school(grade 9-12) & 125 & 21.8 \\
\hline & Collage and above(grade $12+$ ) & 76 & 13.3 \\
\hline \multirow[t]{4}{*}{ Average monthly income in ETB } & $<500$ & 96 & 16.8 \\
\hline & $500-1499$ & 191 & 33.3 \\
\hline & $1500-2500$ & 110 & 19.2 \\
\hline & $>2500$ & 176 & 30.7 \\
\hline \multirow[t]{5}{*}{ Occupation of respondents } & Governmental employ & 70 & 12.2 \\
\hline & NGO employ & 27 & 4.7 \\
\hline & Private worker & 111 & 19.4 \\
\hline & Farmer & 347 & 60.6 \\
\hline & Other & 18 & 3.1 \\
\hline \multirow[t]{3}{*}{ Marital status of respondents } & Married & 439 & 76.6 \\
\hline & Single & 117 & 20.4 \\
\hline & Divorced/widowed & 17 & 3.0 \\
\hline \multirow[t]{3}{*}{ Role in family of respondents } & Father/Mother & 449 & 78.4 \\
\hline & Son & 93 & 16.2 \\
\hline & Daughter & 31 & 5.4 \\
\hline \multirow[t]{2}{*}{ chronic illnesses } & Yes & 500 & 87.3 \\
\hline & No & 73 & 12.7 \\
\hline \multirow[t]{2}{*}{ House ownership } & Yes & $15 \mid$ & 26.4 \\
\hline & No & 422 & 73.6 \\
\hline \multirow[t]{2}{*}{ Distance from health Facility } & Near to health facility & 374 & 65.3 \\
\hline & Long distance $>$ I hour & 199 & 34.7 \\
\hline
\end{tabular}

(Continued) 
Table I (Continued).

\begin{tabular}{|c|c|c|c|}
\hline Variables & Category & Frequency (n) & Percent (\%) \\
\hline \multirow[t]{2}{*}{ Substance use of respondents } & Yes & 188 & 32.8 \\
\hline & No & 385 & 67.2 \\
\hline \multirow{2}{*}{$\begin{array}{l}\text { Information from } \\
\text { Religious leader }\end{array}$} & Yes & 112 & 19.5 \\
\hline & No & 461 & 80.5 \\
\hline \multirow[t]{2}{*}{ Information from radio/ TV } & Yes & 397 & 69.3 \\
\hline & No & 176 & 30.7 \\
\hline \multirow[t]{2}{*}{ Information from Social media } & Yes & 160 & 27.9 \\
\hline & No & 413 & 72.1 \\
\hline \multirow[t]{2}{*}{ Information from Health Worker } & Yes & 46 & 8.0 \\
\hline & No & 527 & 92.0 \\
\hline \multirow[t]{2}{*}{ Information from Announcement } & Yes & 49 & 8.5 \\
\hline & No & 524 & 91.5 \\
\hline
\end{tabular}

Abbreviation: ETB, Ethiopian Birr

evaluating whether the necessary assumptions for the application of multivariable logistic regression were met, as well as whether the model appropriately matched the data $($ Hosmer and Lemeshow test, P-value $=0.30$ ) and multicollinearity was assessed.

\section{Ethical Consideration}

Madda Walabu University's Ethical Review Committee provided ethical clearance and approval. Letter of permission was secured from Bale and East Bale Zones Health Department office. Verbal informed consent was obtained from each study participant and the Madda Walabu University Ethical Review Committee has approved it, and the research was carried out in compliance with the Declaration of Helsinki.

According to this declaration verbal consent was also possible when there were uneducated people. Since some of the respondents had no formal education verbal consent was taken and documented. Anonymity and confidentiality were guaranteed. The participants were made aware that their participation was entirely voluntary. During the interview, data collectors and study participants used sanitizers, masks, and maintained a two-meter distance to prevent the risk of COVID-19.

\section{Results}

\section{Socio-Demographic Characteristic of Participants}

A total of 573 respondents have participated in the study with a response rate of $90.4 \%$. About $213(37.2 \%)$ of the respondents were aged from 25 to 34 years. Primary education (grade 1 to 8 ) account for the highest proportion which was 227 (39.6\%) followed by no formal education (25.3\%). Four hundred fifty-three $(79.10 \%)$ of the respondents were rural residents. Four hundred and thirty-nine $(76.60 \%)$ of the respondents were married (Table 1).

\section{Level of COVID-19-Related Anxiety in the Community Members}

A dysfunctional level of anxiety related to COVID-19 among study participants was 95 (16.58\%). The proportion of respondents with a dysfunctional level of anxiety was $20.93 \%$ among those under the age of 25 , and $11 \%$ among those aged 44 and above with a p-value of 0.26 . Dysfunctional level of anxiety was almost similar among the sex groups which were 62 (16.19\%), 33 (17.37\%) among males and females, respectively, and with a p-value of 0.72 . 


\begin{tabular}{|c|c|c|c|c|c|}
\hline 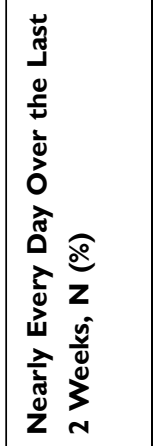 & 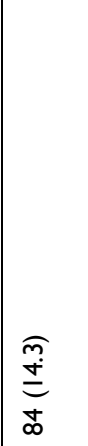 & 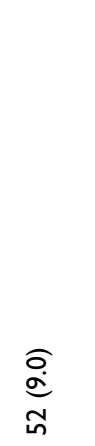 & $\begin{array}{l}\frac{\sigma}{\dot{a}} \\
\underline{m} \\
\underline{m}\end{array}$ & $\frac{\text { F }}{\stackrel{+}{+}}$ & 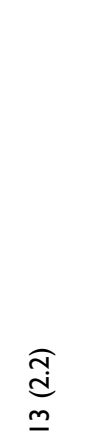 \\
\hline 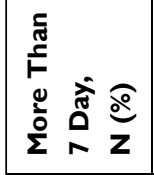 & $\begin{array}{l}\stackrel{\sigma}{\stackrel{S}{=}} \\
=\end{array}$ & $\begin{array}{l}\widehat{\bar{m}} \\
\underline{\infty}\end{array}$ & $\begin{array}{l}\frac{F}{\dot{n}} \\
\frac{m}{m}\end{array}$ & $\begin{array}{l}\widehat{\bar{i}} \\
\underline{\simeq}\end{array}$ & 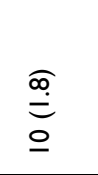 \\
\hline 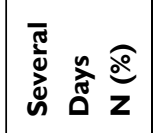 & 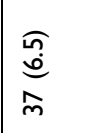 & $\frac{\widehat{m}}{\stackrel{a}{n}}$ & $\begin{array}{l}\stackrel{\sigma}{\hat{\sigma}} \\
\stackrel{\leftrightarrow}{=} \\
\bar{a}\end{array}$ & 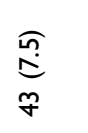 & $\begin{array}{l}\underset{\partial}{ \pm} \\
\tilde{N}\end{array}$ \\
\hline 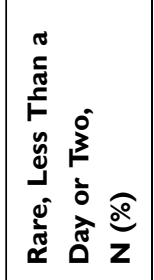 & $\begin{array}{l}\widehat{\overline{0}} \\
\stackrel{0}{0} \\
\stackrel{i}{0}\end{array}$ & $\begin{array}{l}\underset{i}{\dot{j}} \\
\underset{n}{\tilde{N}}\end{array}$ & 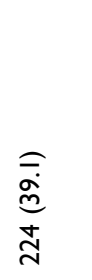 & 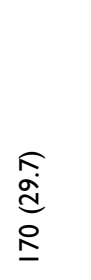 & 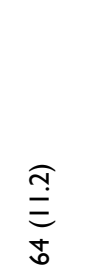 \\
\hline 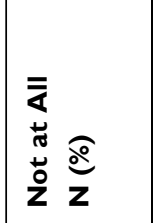 & 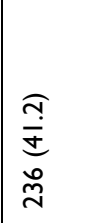 & $\begin{array}{l}\widehat{\sigma} \\
\stackrel{n}{n} \\
\hat{N}\end{array}$ & 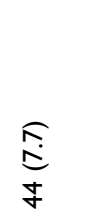 & $\begin{array}{l}\sigma \\
\dot{0} \\
\stackrel{0}{n} \\
\bar{m}\end{array}$ & $\begin{array}{l}\widehat{\alpha} \\
\dot{0} \\
\dot{\infty} \\
m \\
\dot{f}\end{array}$ \\
\hline $\begin{array}{l}\stackrel{\mathscr{E}}{\Phi} \\
\underline{\underline{N}}\end{array}$ & 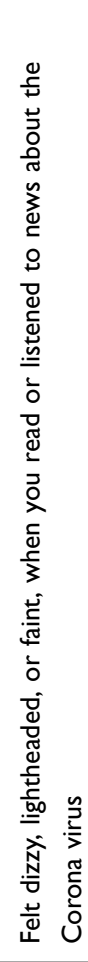 & 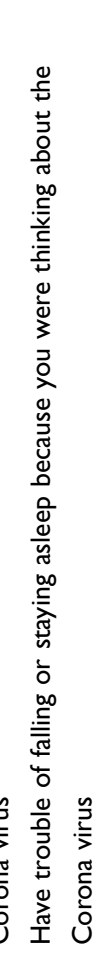 & 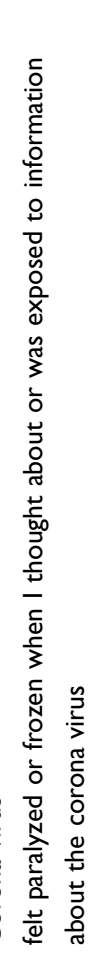 & 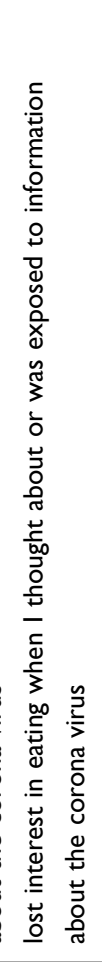 & 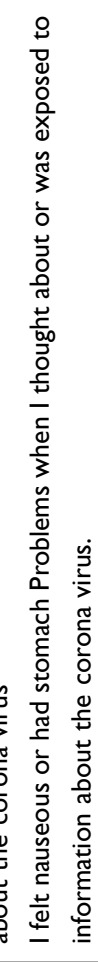 \\
\hline
\end{tabular}

Concerning anxiety about the coronavirus during the past two weeks, prior to data collection; about half (54.6\%) of the participants spent several days feeling elevated anxiety. In our study, over the last 2 weeks prior to data collection, about $31.9 \%$ of the study participants had felt paralyzed or frozen nearly every day, while $15.9 \%$ of participants had felt paralyzed or frozen for several days. The participants had felt dizzy, lightheaded, or faint $14.3 \%$ nearly every day over the last 2 weeks, more than 7 days $1.9 \%$, and several day $6.5 \%$ (Table 2 ).

\section{Coping Strategies Towards COVID-19- Related Anxiety Among the Community Members}

About half, 290 (50.6\%) respondents coped with anxiety that occurred as a result of COVID-19. The proportion of study participants who coped with anxiety due to COVID19 were $216(47.68 \%)$ in rural and 74 (61.67\%) in urban. Respondents who have chronic illness coped from anxiety related to COVID-19 were 38 (52.05\%) and the remaining variables are explained in Table 3. Findings of the current study reveal that $75.5 \%$ and $18.9 \%$ of study participants had tended to lie sick in bed always and medium amount, respectively (Table 4 ).

\section{Factors Associated with the Level of COVID-19-Related Anxiety Among Community Members}

In the multivariable logistic model, residence $(\mathrm{p}=0.017)$, distance from the health facility $(\mathrm{p}=0.037)$, and source of information from $\mathrm{TV} /$ radio $(\mathrm{p}=0.020)$ were statistically significant variables (Table 5).

The odds of having a dysfunctional level of anxiety among study participants of the urban resident were $56 \%$ less likely ( $\mathrm{AOR}=0.44,95 \% \mathrm{CI}: 0.23,0.86)$ as compared to rural residents. Those respondents who have no information from TV/radio-related COVID-19 had 1.76 times (AOR $=1.76,95 \%$ CI: 1.09, 2.84) higher odds of having dysfunctional anxiety than their counterpart. The odds of having dysfunctional anxiety was reduced by $42 \%$ $(\mathrm{AOR}=0.58,95 \% \mathrm{CI}: 0.34,0.97)$ in respondents walking long distance of more than 1 hour as compared to those residing near a health facility.

\section{Discussion}

This study aimed to assess levels of anxiety and coping strategies in the communities of Bale Zone and East Bale 
Table 3 Copying Strategies from Anxiety Due to COVID-19 in Relation to the Socio-Demographic Characteristics of Respondents Among Communities of Bale Zones, Southeast Ethiopia,2020 $(n=573)$

\begin{tabular}{|c|c|c|c|}
\hline \multirow[t]{2}{*}{ Variables } & \multirow[t]{2}{*}{ Category } & \multicolumn{2}{|c|}{ Coping Strategies } \\
\hline & & $\begin{array}{l}\text { Coped } \\
\text { Frequency (\%) }\end{array}$ & $\begin{array}{l}\text { No coped } \\
\text { Frequency (\%) }\end{array}$ \\
\hline \multirow[t]{4}{*}{ Age of respondents } & $<25$ & $64(49.61)$ & 65(50.39) \\
\hline & $25-34$ & II 15 (53.99) & $98(46.01)$ \\
\hline & $35-44$ & $55(52.38)$ & $50(47.62)$ \\
\hline & $>44$ & $56(44.44)$ & $70(55.56)$ \\
\hline \multirow[t]{2}{*}{ Gender } & Male & $198(51.70)$ & $185(48.30)$ \\
\hline & Female & $92(48.42)$ & $98(51.58)$ \\
\hline \multirow[t]{2}{*}{ Residence } & Rural & $216(47.68)$ & $237(52.32)$ \\
\hline & Urban & $74(6 I .67)$ & $46(38.33)$ \\
\hline \multirow[t]{4}{*}{ Level of education } & No formal education & $59(40.69)$ & $86(59.31)$ \\
\hline & primary education (I-8) & $106(46.70)$ & $|2|(53.30)$ \\
\hline & Secondary school (9-12) & $66(52.80)$ & $59(47.20)$ \\
\hline & Collage and above $(12+)$ & $59(77.63)$ & $17(22.37)$ \\
\hline \multirow[t]{4}{*}{ Average monthly income ETB } & $<500$ & 38 (39.58) & $58(60.42)$ \\
\hline & $500-1499$ & $82(42.93)$ & $109(57.07)$ \\
\hline & $1500-2500$ & $59(53.64)$ & 51 (46.36) \\
\hline & $>2500$ & III (63.07) & $65(36.93)$ \\
\hline \multirow[t]{5}{*}{ Occupation } & Governmental employ & $53(75.71)$ & $17(24.29)$ \\
\hline & NGO employ & $20(74.07)$ & $7(25.9)$ \\
\hline & Private worker & $62(55.86)$ & $49(44.14)$ \\
\hline & Farmer & I $44(4 \mid .50)$ & $203(58.50)$ \\
\hline & Other & II (6I.II) & 7 (38.89) \\
\hline \multirow[t]{3}{*}{ Marital status } & Married & 219 (49.89) & $220(50.11)$ \\
\hline & Single & $64(54.70)$ & $53(45.30)$ \\
\hline & Divorced/widowed & $7(4|| 8)$. & $10(58.82)$ \\
\hline \multirow[t]{3}{*}{ Role in the family } & Father/Mother & $219(48.78)$ & $230(51.22)$ \\
\hline & Son & $54(58.06)$ & $39(41.94)$ \\
\hline & Daughter & $17(54.84)$ & $14(45.160$ \\
\hline \multirow[t]{2}{*}{ chronic illnesses } & Yes & $38(52.05)$ & 35 (47.95) \\
\hline & No & $252(50.40)$ & $248(49.60)$ \\
\hline \multirow[t]{2}{*}{ House ownership } & Yes & $211(50.00)$ & $211(50.00)$ \\
\hline & No & 79 (52.32) & $72(47.68)$ \\
\hline
\end{tabular}

(Continued) 
Table 3 (Continued).

\begin{tabular}{|c|c|c|c|}
\hline \multirow[t]{2}{*}{ Variables } & \multirow[t]{2}{*}{ Category } & \multicolumn{2}{|c|}{ Coping Strategies } \\
\hline & & $\begin{array}{l}\text { Coped } \\
\text { Frequency (\%) }\end{array}$ & $\begin{array}{l}\text { No coped } \\
\text { Frequency (\%) }\end{array}$ \\
\hline \multirow{2}{*}{$\begin{array}{l}\text { Distance from health } \\
\text { Facility }\end{array}$} & Near to health facility & $220(58.82)$ & $154(41.18)$ \\
\hline & Long distance $>$ I hour & $70(35.18)$ & $129(64.82)$ \\
\hline \multirow[t]{2}{*}{ Substance use } & Yes & $94(50.00)$ & $94(50)$ \\
\hline & No & $196(51.00)$ & $189(49.09)$ \\
\hline \multirow{2}{*}{$\begin{array}{l}\text { Information from } \\
\text { Religious leader }\end{array}$} & Yes & $42(37.50)$ & $70(62.500)$ \\
\hline & No & $248(53.80)$ & $213(46.20)$ \\
\hline \multirow[t]{2}{*}{ Information from radio/ TV } & Yes & $200(50.38)$ & 197(49.62) \\
\hline & No & $90(51.14)$ & $86(48.86)$ \\
\hline \multirow[t]{2}{*}{ Information from Social media } & Yes & $95(59.38)$ & $65(40.63)$ \\
\hline & No & $195(47.22)$ & $218(52.78)$ \\
\hline \multirow[t]{2}{*}{ Information from Health Worker } & Yes & $17(36.96)$ & $29(63.04)$ \\
\hline & No & $273(51.80)$ & $254(48.20)$ \\
\hline \multirow[t]{2}{*}{ Information from Announcement } & Yes & $25(51.02)$ & $24(48.98)$ \\
\hline & No & $265(50.57)$ & $259(49.43)$ \\
\hline
\end{tabular}

Zone, Southeast Ethiopia. According to the findings of the current study $16.58 \%$ (95CI: $13.8 \%, 19.9 \%$ ) of the study participants had dysfunctional anxiety related to COVID19. This study is in line with the findings of the study conducted in Singapore $(14.5 \%){ }^{22}$

These rates of prevalence are lower than those reported from China $(70.78 \%),(22.6 \%),(25 \%),{ }^{5,23,24}$ and $(28.8 \%){ }^{25}$ This might be the reason why the Tang F et al study conducted in China was among quarantined respondents, in which mental health was worse in the quarantined area than in un-quarantined areas, and deteriorated most in the quarantined unaffected areas, depression and anxiety were common mental health problems among people in quarantine. In addition to this, the continuous spread of the epidemic, strict isolation measures, and delays in starting schools, colleges, and universities across the country is expected to influence the mental health of college students. College students' anxiety about COVID-19 might have been related to the effect of the virus on their studies ${ }^{26}$ and future employment. ${ }^{24}$
On the other hand, the students' anxiety may have been caused by the gradually increasing distances between people resulting from the quarantine. It is known that anxiety disorders are more likely to occur and worsen in the absence of interpersonal communication. ${ }^{27}$ Furthermore, during the COVID-19 outbreak, disinformation and false reports about the COVID-19 have bombarded social media and stoked unfounded fears among many citizens, which may confuse people and harm people's mental health. ${ }^{28}$ Also, many citizens expressed their negative feelings, such as fear, worry, nervousness, and anxiety.

According to the finding of our study, about half $50.6 \%$ (95CI: $46.5 \%, 54.7 \%$ ) of study participants were coped with anxiety related to COVID-19, this may be more of the study participants are from the rural part which did not have enough knowledge (understanding) and lacks reliable information or facts related to COVID-19.

Multivariable logistic regression analysis showed that those respondents who had no information from TV/radio-related COVID-19 had 1.76 times higher 
Table 4 Respondents Coping Strategies from Anxiety Due to COVID-19 Among Communities of Bale Zones, Southeast Ethiopia, $2020(n=573)$

\begin{tabular}{|c|c|c|c|c|}
\hline Items & $\begin{array}{l}\text { Never } \\
\text { N (\%) }\end{array}$ & $\begin{array}{l}\text { A Little } \\
\text { Bit } \\
\text { N (\%) }\end{array}$ & $\begin{array}{l}\text { A Medium Amount, } \mathbf{N} \\
\text { (\%) }\end{array}$ & $\begin{array}{l}\text { Always } \\
\text { N (\%) }\end{array}$ \\
\hline Can you follow a lot of directions at once, even in a crisis & $138(24.1)$ & $334(58.3)$ & $49(8.6)$ & $52(9.1)$ \\
\hline Did you call the problem what it is and try to see the whole picture & $95(16.6)$ & $295(51.5)$ & $89(15.5)$ & $94(16.4)$ \\
\hline $\begin{array}{l}\text { Did you gather as much information as possible to increase my } \\
\text { options }\end{array}$ & $45(7.8)$ & $233(40.7)$ & $96(16.8)$ & $\begin{array}{l}199 \\
(34.7)\end{array}$ \\
\hline Generally try to make everything work in my favor & $53(9.3)$ & $309(53.9)$ & $94(16.4)$ & $\begin{array}{l}117 \\
(20.4)\end{array}$ \\
\hline Can think of nothing else, except what's bothering me & $69(12.0)$ & $84(14.7)$ & $217(37.9)$ & $\begin{array}{l}203 \\
(35.4)\end{array}$ \\
\hline Try to get more resources to deal with the situation & $86(15.0)$ & $303(52.8)$ & $92(16.1)$ & $92(16.1)$ \\
\hline Use humor in handling the situation & $38(6.6)$ & $321(56.0)$ & $100(17.5)$ & $\begin{array}{l}114 \\
(19.9)\end{array}$ \\
\hline Can solve problems more effectively under stress & $71(12.4)$ & $339(59.2)$ & $79(13.7)$ & $84(14.7)$ \\
\hline $\begin{array}{l}\text { Take strength from spirituality or the successes of courageous } \\
\text { people }\end{array}$ & $36(6.3)$ & $168(29.3)$ & $112(19.6)$ & $\begin{array}{l}257 \\
(44.8)\end{array}$ \\
\hline Can benefit from my past experiences for what is happening now & $90(15.7)$ & $311(54.3)$ & $100(17.5)$ & $72(12.5)$ \\
\hline Try to be creative and come up with a new solution & $256(44.7)$ & $223(38.9)$ & $59(10.3)$ & $35(6.1)$ \\
\hline $\begin{array}{l}\text { Brainstorm as many possible solutions as I can even if they seem far } \\
\text { out }\end{array}$ & $228(39.8)$ & $230(40.1)$ & $45(7.9)$ & $70(12.2)$ \\
\hline Tend to lie sick in bed & $13(2.3)$ & $19(3.3)$ & $108(18.9)$ & $\begin{array}{l}433 \\
(75.5)\end{array}$ \\
\hline Give up easily too often & $32(5.6)$ & $35(6.1)$ & $170(29.7)$ & $\begin{array}{l}336 \\
(58.6)\end{array}$ \\
\hline Develop a plan with a series of actions to deal with the event & $178(3 \mid .0)$ & $267(46.6)$ & $68(11.9)$ & $60(10.5)$ \\
\hline
\end{tabular}

odds of having dysfunctional anxiety than their counterparts. Unexpectedly, these findings indicated more dysfunctional anxiety among study participants who had no information from TV/radio regardingCOVID-19. This finding contradicts to the previous study, where social media exposures were associated with higher anxiety. ${ }^{29}$ This could be justified as evidence showed that during a severe social change due to pandemic, there is usually a high need for information and sense seeking by individuals and the mass media are generally perceived to best satisfy these needs. ${ }^{30}$ In particular, the general public depend closely on the media to obtain information regarding pandemic guidance to the public on the response. One of the reasons why people usually need more information in the context of pandemic time is to reduce the anxiety caused by uncertainty in the pandemic time. ${ }^{31,32}$ Research indicated that in the pandemic/epidemic time, uncertainty and uncontrollable feelings were positively related to anxiety. ${ }^{33}$ In addition to this lack of household electric broadcast facilities, such as TV or radio, may hinder them to have the real information such as its severity, way of transmission, and how to prevent pandemic because much of communication by government and health agencies is done via 


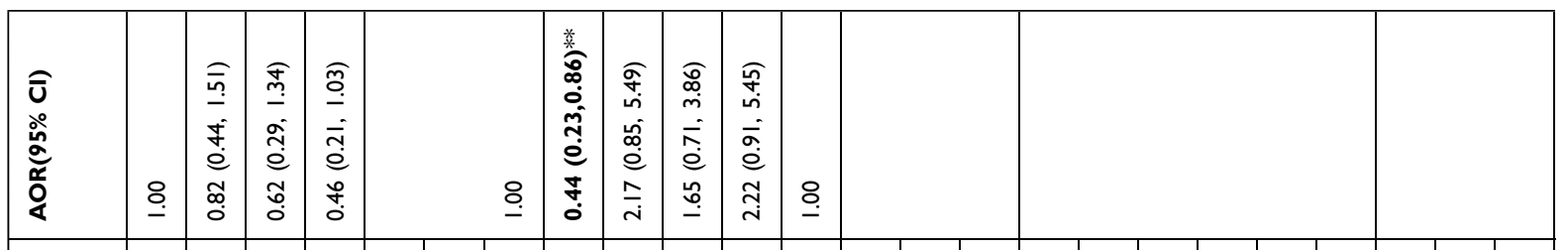

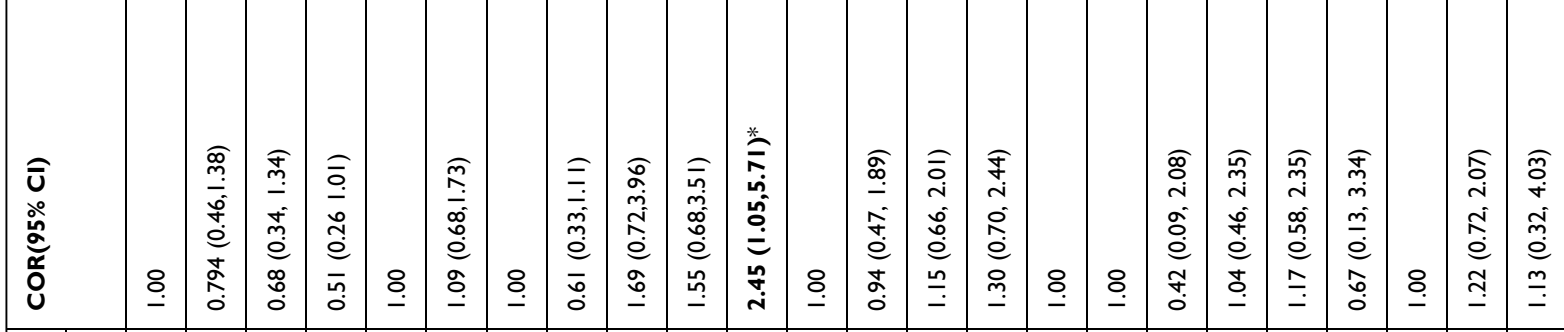

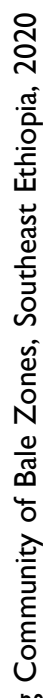
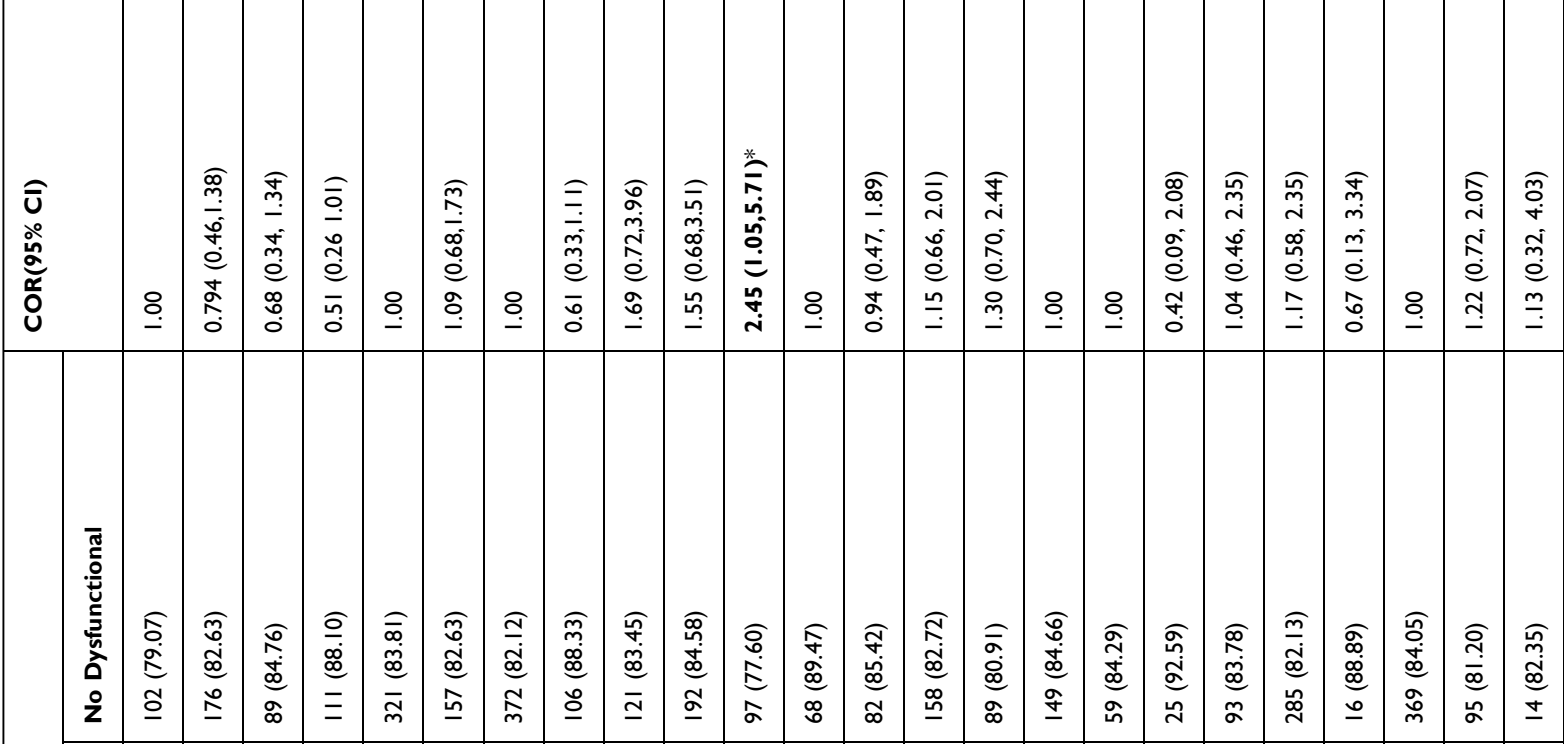

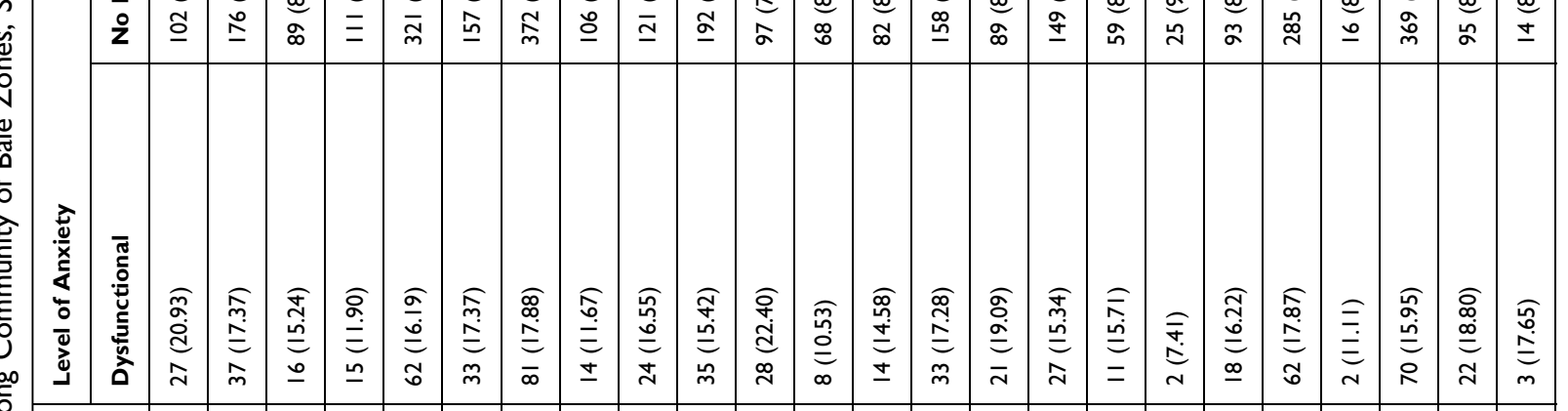

ฮู

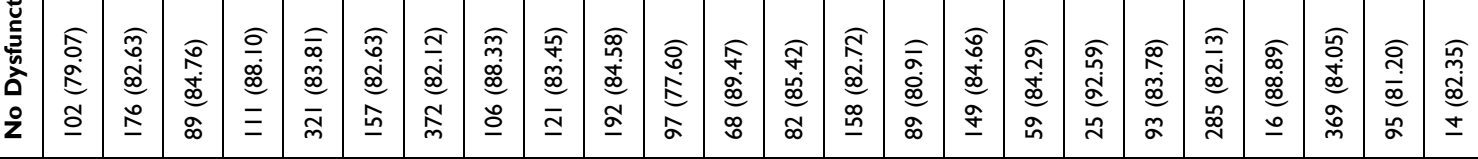

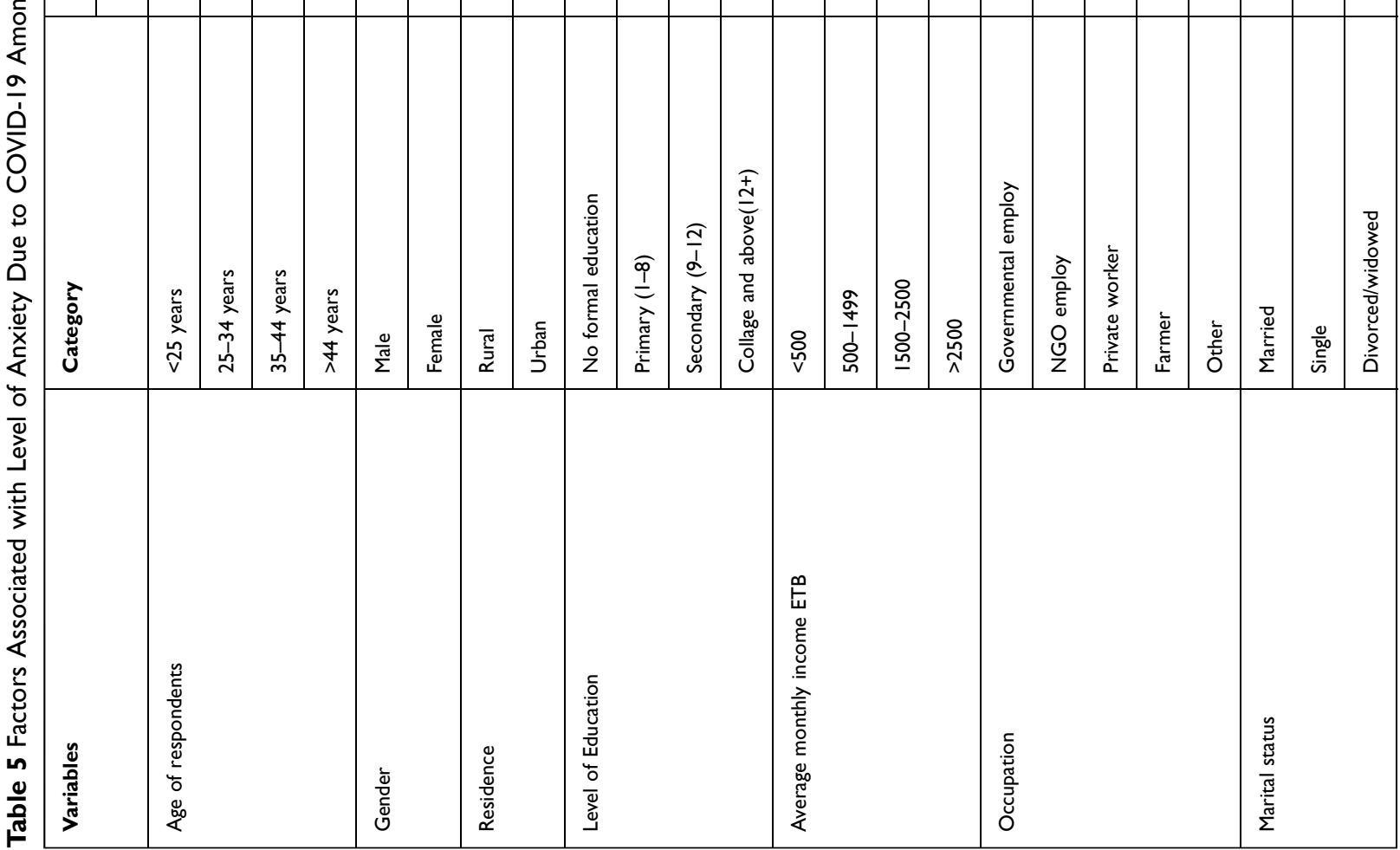




\begin{tabular}{|c|c|c|c|c|c|c|c|c|c|c|c|c|c|c|c|c|c|c|c|c|c|}
\hline & & & & & & & & & & & \&: & & & $\stackrel{8}{8}$ & 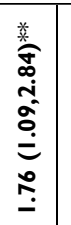 & & & & & & \\
\hline 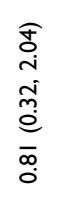 & 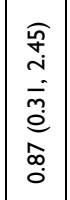 & $\stackrel{8}{8}$ & 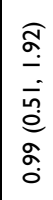 & $\stackrel{8}{8}$ & 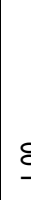 & 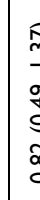 & & & 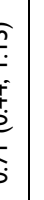 & & 8 & $\stackrel{8}{-}$ & 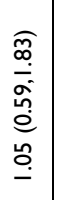 & $\stackrel{8}{\circ}$ & 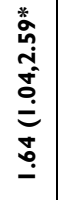 & $\stackrel{8}{\circ}$ & 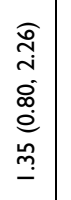 & $\stackrel{0}{\circ}$ & 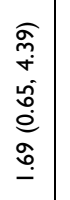 & $\stackrel{.}{.}$ & 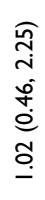 \\
\hline 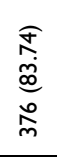 & 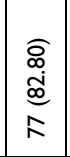 & 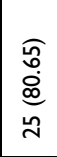 & 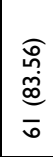 & 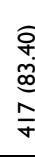 & 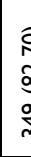 & 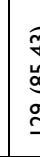 & & 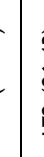 & 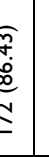 & 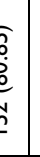 & 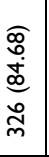 & 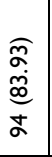 & 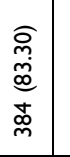 & 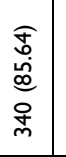 & 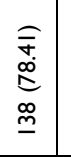 & 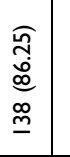 & $\begin{array}{l}\widehat{\widetilde{N}} \\
\tilde{\infty} \\
0 \\
0 \\
\tilde{m}\end{array}$ & $\begin{array}{c}\frac{\widehat{m}}{\dot{\alpha}} \\
\stackrel{\alpha}{\sigma} \\
\bar{\sigma}\end{array}$ & $\begin{array}{l}\widehat{\sigma} \\
\hat{\infty} \\
\hat{\alpha} \\
\hat{\sigma}\end{array}$ & 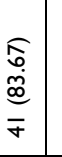 & 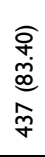 \\
\hline 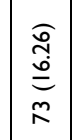 & \begin{tabular}{|l|l} 
& $\widehat{9}$ \\
\\
$\underline{0}$ \\
\end{tabular} & 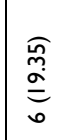 & 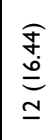 & 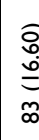 & $\tilde{1}$ & & & & م. & 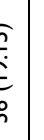 & 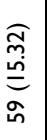 & 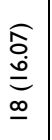 & 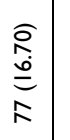 & 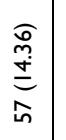 & 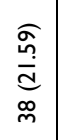 & 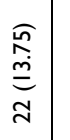 & 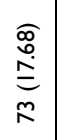 & 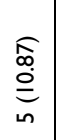 & $\begin{array}{l}\mathbf{0} \\
\stackrel{0}{1} \\
\vdots \\
\vdots\end{array}$ & 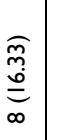 & 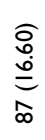 \\
\hline
\end{tabular}

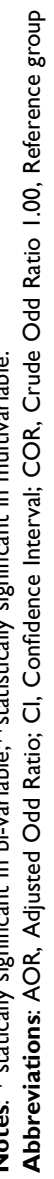


mass media. The source of information for these people is mainly simple talks and saying from persons in the community. Even anxiety might not be only regarding the pandemic, it may also relate with thinking from where to acquire the right information.

Study participants from urban residents were less likely to have dysfunctional anxiety by $56 \%$ as compared to study participants from rural residents. This finding is similar to a study conducted in China. ${ }^{24}$ The possible reason for these could be that urban residents are relatively more educated, economically improved, have better information from media, accessible infrastructure, and improved technologies.

Walking a long distance of more than 1 hour from the health facility was significantly associated with a lower risk of dysfunctional anxiety by $42 \%$ than those residing near the health facility. This might be due to those respondents who are near the health facility frequently hearing about the risk of transmission of this contagious disease and may have information about those suspected, confirmed cases, and deaths related to COVID-19 which in turn may increase the level of dysfunctional anxiety. In addition to this, anxiety-related factors like the exposure to close contacts with those COVID-19 exposed individuals also aggravate their psychological problems. ${ }^{34}$

\section{Limitation of Study}

The cross-sectional design of this study precludes drawing conclusions regarding causality or temporal precedence. Employing tools that use self-reported data to assess the severity of symptoms of anxiety-related COVID-19 and the frequency of usage of a coping strategy.

\section{Conclusion}

Findings from the current study revealed that about one out of six of the study participants had COVID-19-related dysfunctional anxiety and nearly half of them coped with COVID-19-related anxiety. Residence, distance from health facility, and information from radio/TV were statistically significant variables to COVID-19-related dysfunctional level of anxiety among the study community. Accordingly, being an urban dweller and walking a long distance of more than 1 hour from the health facility were the factors that decreased the odds of having dysfunctional anxiety, whereas respondents who had no information from radio/TV increased the odds of having dysfunctional anxiety-related COVID-19. It is good if the concerned health programmer gives priority in rural areas to disseminate reliable, scientifically supported, and timely information for the community regarding pandemic COVID-19. It is also better if the concerned body considers factors identified in this study and puts them into action. It is also recommended that health workers frequently create awareness about COVID-19, which may have a multiplier effect to decrease the dysfunctional levels of anxiety and increase coping in the community.

\section{Abbreviations}

AOR, Adjusted Odd Ratio; CAS, Corona Anxiety Scale; CAPS, Coping and Adaptation Process Scale; CI, Confidence Interval; COR, Crude Odd Ratio; COVID, Coronavirus Disease.

\section{Data Sharing Statement}

The datasets used and analyzed during the current study are available from the corresponding authors on reasonable request.

\section{Acknowledgments}

We would like to thank Madda Walabu for funding this study and study participants, data collectors, and Bale Zone health bureau.

\section{Author Contributions}

All authors made substantial contributions to conception and design, acquisition of data, or analysis and interpretation of data; took part in drafting the article or revising it critically for important intellectual content; agreed to submit to the current journal; gave final approval for the version to be published; and agreed to be accountable for all aspects of the work.

\section{Funding}

Funded by Madda Walabu University.

\section{Disclosure}

The authors declare that there are no competing interests.

\section{References}

1. Zhu N, Zhang D, Wang W, et al. A novel coronavirus from patients with pneumonia in China, 2019. N Engl J Med. 2020;382(8):727-733. doi:10.1056/NEJMoa2001017

2. Shacham M, Hamama-Raz Y, Kolerman R, Mijiritsky O, Ben-Ezra M, Mijiritsky E. COVID-19 factors and psychological factors associated with elevated psychological distress among dentists and dental hygienists in Israel. Int J Environ Res Public Health. 2020;17(8):2900. 
3. WHO. Coronavirus disease (COVID-19) Pandemic Available from: https://www.who.int/emergencies/diseases/novel-coronavirus-2019. Accessed June 23, 2021.

4. Zhang J, Wu W, Zhao X, Zhang W. Recommended psychological crisis intervention response to the 2019 novel coronavirus pneumonia outbreak in China: a model of West China Hospital. Precision Clinical Medicine. 2020;3(1):3-8.

5. Tang F, Liang J, Zhang H, Kelifa MM, He Q, Wang P. COVID-19 related depression and anxiety among quarantined respondents. Psychol Health. 2020;1-15.

6. Xiang Y-T, Yang Y, Li W, et al. Timely mental health care for the 2019 novel coronavirus outbreak is urgently needed. Lance Psychiatry. 2020;7(3):228-229.

7. Banerjee D. The COVID-19 outbreak: crucial role the psychiatrists can play. Asian J Psychiatr. 2020;50:102014.

8. Lee J. Mental health effects of school closures during COVID-19. Lancet Child Adolescent Health. 2020;4(6):421.

9. Wang C, Pan R, Wan X, et al. Immediate psychological responses and associated factors during the initial stage of the 2019 coronavirus disease (COVID-19) epidemic among the general population in China. Int J Environ Res Public Health. 2020;17(5):1729.

10. Bao Y, Sun Y, Meng S, Shi J, Lu L. 2019-nCoV epidemic: address mental health care to empower society. The Lancet. 2020;395 (10224):e37-e8.

11. Dar KA, Iqbal N, Mushtaq A. Intolerance of uncertainty, depression, and anxiety: examining the indirect and moderating effects of worry. Asian J Psychiatr. 2017;29:129-133.

12. Goyal K, Chauhan P, Chhikara K, Gupta P, Singh MP. Fear of COVID 2019: first suicidal case in India! Asian journal of psychiatry. 2020;49:101989.

13. Srivatsa S, Stewart KA. How should clinicians integrate mental health into epidemic responses? AMA J Ethics. 2020;22(1):10-15.

14. Home O. COVID-19: Protecting people and societies.

15. Bish A, Michie S. Demographic and attitudinal determinants of protective behaviors during a pandemic: a review. $\mathrm{Br} J$ Health Psychol. 2010;15(4):797-824.

16. Taylor S, Asmundson GJ. Treating Health Anxiety: A CognitiveBehavioral Approach: Guilford Press; 2004.

17. W B. Calculating the Sample Size for Surveys of the Prevalence of Tuberculosis. Combodia; 2006. Available from: http://www.tbrieder. org/publications.

18. Darega B, Dida N, Tafese F, Ololo S. Institutional delivery and postnatal care services utilization in Abuna Gindeberet District, West Shewa, Oromiya Region, Central Ethiopia: a Communitybased cross- sectional study. BMC Pregnancy Childbirth. 2016;16 (1): 149 .

19. Lee SA. Coronavirus Anxiety Scale: a brief mental health screener for COVID-19 related anxiety. Death Stud. 2020;44(7):393-401.
20. APA. American Psychiatric Association (APA). (2013).Diagnostic and statistical manual of mental disorders 2013https://www.google. com $/$ search?client $=$ firefox-bd\&q=American + Psychiatric + Association $+\% 28$ APA \%29.+\%282013\%29.Diagnostic+and+statistical+manual + of + mental + disorders $+\% 285$ th + ed.\%29.+Author. Accessed June 23, 2021.

21. Roy S Coping and Adaptation Processing Scale (CAPS): Short Form (15-Item) information for Users. 2016.

22. Liu N, Zhang F, Wei C, et al. Prevalence and predictors of PTSS during COVID-19 outbreak in China hardest-hit areas: gender differences matter. Psychiatry Res. 2020;112921.

23. Cao W, Fang Z, Hou G, et al. The psychological impact of the COVID-19 epidemic on college students in China. Psychiatry Res. $2020 ; 112934$.

24. Gao J, Zheng P, Jia Y, et al. Mental health problems and social media exposure during COVID-19 outbreak. Plosone. 2020;15(4): e0231924.

25. Fardin MA. COVID-19 and anxiety: A review of psychological impacts of infectious disease outbreaks. Archives of clinical infectious diseases. 2020; 15(COVID-19).

26. Cornine A. Reducing nursing student anxiety in the clinical setting: an integrative review. Nurs Educ Perspect. 2020;41(4):229-234.

27. Xiao C. A novel approach of consultation on 2019 novel coronavirus (COVID-19)-related psychological and mental problems: structured letter therapy. Psychiatry Investig. 2020;17(2):175.

28. Gao J, Zheng P, Jia Y, et al. Mental health problems and social media exposure during COVID-19 outbreak. PLoS One. 2020;15(4): e0231924.

29. Neria Y, Sullivan GM. Understanding the mental health effects of indirect exposure to mass trauma through the media. JAMA. 2011;306 (12):1374-1375.

30. Lowrey W. Media dependency during a large-scale social disruption: the case of September 11. Mass Commun Soci. 2004;7(3):339-357.

31. Brashers DE, Neidig JL, Haas SM, Dobbs LK, Cardillo LW, Russell Ja. Communication in the management of uncertainty: the case of persons living with HIV or AIDS. Commun Monographs. 2000;67 (1):63-84.

32. Chen CY, Hong RY. Intolerance of uncertainty moderates the relation between negative life events and anxiety. Pers Individ Dif. 2010;49 (1):49-53

33. Taha SA, Matheson K, Anisman H. H1N1 was not all that scary: uncertainty and stressor appraisals predict anxiety related to a coming viral threat. Stress Health. 2014;30(2):149-157.

34. Kang L, Ma S, Chen M, et al. Impact on mental health and perceptions of psychological care among medical and nursing staff in Wuhan during the 2019 novel coronavirus disease outbreak: a cross-sectional study. Brain Behav Immun. 2020.
Psychology Research and Behavior Management

\section{Publish your work in this journal}

Psychology Research and Behavior Management is an international, peer-reviewed, open access journal focusing on the science of psychology and its application in behavior management to develop improved outcomes in the clinical, educational, sports and business arenas. Specific topics covered in the journal include: Neuroscience, memory and decision making; Behavior modification and management; Clinica applications; Business and sports performance management; Social and developmental studies; Animal studies. The manuscript management system is completely online and includes a very quick and fair peer-review system, which is all easy to use. Visit http://www. dovepress.com/testimonials.php to read real quotes from published authors. 